\title{
Sleep apnoea in patients with quadriplegia
}

\author{
R Douglas McEvoy, Ivanka Mykytyn, Dimitar Sajkov, Howard Flavell, Ruth Marshall, \\ Ral Antic, Andrew T Thornton
}

\begin{abstract}
Background - This study was undertaken to establish the prevalence of, and the factors contributing towards, sleep disordered breathing in patients with quadriplegia.

Methods - Forty representative quadriplegic patients (time since injury $>6$ months, injury level $\mathrm{C8}$ and above, Frankel category $A, B$, or $C$; mean (SE) age $35 \cdot 0(1 \cdot 7)$ years) had home sleep studies in which EEG, EOG, submental EMG, body movement, nasal airflow, respiratory effort, and pulse oximetry $\left(\mathrm{SpO}_{2}\right)$ were measured. Patients reporting post traumatic amnesia of $>24$ hours, drug or alcohol abuse or other major medical illness were excluded from the study. A questionnaire on medications and sleep was administered and supine blood pressure, awake $\mathrm{Spo}_{2}$, spirometric values, height, and neck circumference were measured.
\end{abstract}

Results - A pattern of sustained hypoventilation was not observed in any of the patients. Sleep apnoeas and hypopnoeas were, however, common. Eleven patients $(27 \cdot 5 \%)$ had a respiratory disturbance index (RDI, apnoeas plus hypopnoeas per hour of sleep) of $\geqslant 15$, with nadir $\mathrm{SpO}_{2}$ ranging from $49 \%$ to $95 \%$. Twelve of the $40(30 \%)$ had an apnoea index (AI) of $\geqslant 5$ and, of these, nine $(75 \%)$ had predominantly obstructive apnoeas - that is, $\mathbf{> 8 0} \%$ of apnoeas were obstructive or mixed. This represents a prevalence of sleep disordered breathing more than twice that observed in normal populations. For the study population RDI correlated with systolic and diastolic blood pressure and neck circumference. RDI was higher in patients who slept supine compared with those in other postures. Daytime sleepiness was a common complaint in the study population and sleep architecture was considerably disturbed with decreased REM sleep and increased stage 1 non-REM sleep.

Conclusions - Sleep disordered breathing is common in quadriplegic patients and sleep disturbance is significant. The predominant type of apnoea is obstructive. As with non-quadriplegic patients with sleep apnoea, sleep disordered breathing in quadriplegics is associated with increased neck circumference and the supine sleep posture.

(Thorax 1995;50:613-619)

Keywords: quadriplegia, sleep, sleep apnoea.
There are a number of theoretical reasons why quadriplegic patients may be prone to disordered breathing in sleep. Firstly, intercostal and abdominal muscles are paralysed, and in patients with high lesions (C5 and above) the action of the diaphragm is also impaired. It is known from other studies that patients with respiratory muscle weakness are prone to sleep disordered breathing. ${ }^{1}$ Secondly, most quadriplegic patients take medication to suppress painful or distressing muscle spasms. Benzodiazepines have been shown to increase the frequency and severity of disordered breathing events in sleep ${ }^{2-4}$ and baclofen, also used to treat muscle spasms, has the potential to do the same because of its depressant effects on the central nervous system. ${ }^{5}$ Thirdly, recent evidence suggests that there may be significant differences between quadriplegics and normal subjects in their compensatory reflex responses to resistive or elastic respiratory loads. ${ }^{6}$ It is possible that these differences may predispose quadriplegics to more upper airway obstruction or hypoventilation in sleep.

We recently showed, in a small group of quadriplegic patients, a relatively high prevalence of severe episodic nocturnal hypoxia. The pattern of oxygen desaturation and the presence of audible snoring in most of the patients studied raised the possibility of obstructive sleep apnoea. However, sleep, respiratory effort and airflow were not measured in that study and the type of respiratory disturbance could not be determined. Other preliminary reports have also suggested that sleep disordered breathing, either central or obstructive, may be common in quadriplegia. ${ }^{8-10}$ A recent report of 22 patients with spinal cord lesions aged over 40 showed clearly abnormal obstructive apnoea patterns in six patients $(27 \%) .{ }^{11}$ Generally, however, the numbers of patients in these earlier studies have been too small, or the study populations biased, to permit a proper estimate of the prevalence of sleep disordered breathing in quadriplegia and to determine which patients are at greatest risk. The aim of the present study was to provide such information. We report the findings of detailed overnight sleep and breathing measurements made in the homes of 40 quadriplegic patients.

\section{Methods}

PATIENT SELECTION

Our aim was to study all quadriplegic patients currently living in the state of South Australia who met the following selection criteria: (1) age between 18 and 60 years inclusive; (2) 
spinal cord injury level C8 or above classified as Frankel A, B or C; and (3) injury sustained six months or more before study. Frankel category A refers to complete motor function and sensory loss below the level of the lesion; category $\mathrm{B}$, complete motor function loss with some sensory sparing; and category C, some sensory sparing and some non-functional motor sparing. Patients were excluded if they had chronic cardiopulmonary disease, alcohol or drug abuse at the time of the study, or a history of head injury resulting in post traumatic amnesia of more than 24 hours. Patients with other neurological diseases or a history of psychiatric illness were also excluded.

\section{PATIENT RECRUITMENT}

A national registry of spinal injured patients was used to identify all patients who sustained a spinal cord injury C8 or above in South Australia between 1976 and 1990 and who met the age and time since injury criteria. These patients were then sent a letter inviting them to participate in the study and were asked to complete and return a questionnaire regardless of whether they wished to proceed to the overnight sleep study. The questionnaire asked a number of questions concerning sleep, choking episodes in sleep, snoring, daytime sleepiness, current medications, alcohol consumption and past head injury. In addition, we searched records for the same period (1976-1990) in the two institutions in South Australia that were likely to have had contact with other patients who sustained their injury in another state but subsequently moved to South Australia. Those patients who returned questionnaires and agreed to participate in sleep studies were then personally visited and examined by one of the investigators (HF) to confirm that they currently met all selection criteria.

\section{SLEEP STUDIES}

Night time polysomnographic studies were performed on patients in their own homes using a portable device that recorded multiple channels of physiological information on magnetic tape (Oxford, Medilog MPA-2, Oxford, UK). Sleep scoring (screen by screen) using this device has been shown to be as reliable as polygraph chart paper scoring. ${ }^{12}$ The following parameters were recorded: electroencephalogram (EEG) (C3/A2), submental electromyogram (EMG), bilateral oculograms (EOG), abdominal respiratory movement (inductive plethysmography), airflow (oronasal thermistor), and finger probe pulse oximetry $\left(\mathrm{SpO}_{2}\right)$. A single channel of respiratory effort was used because of the limitation of total channels available for recording and because we reasoned that paradoxical thoracoabdominal motion is always present in this population and, therefore, is unhelpful in detecting upper airways obstruction. In addition, a pair of surface electrodes was placed on the anterior thigh in an attempt to detect any muscle spasms during the night that may have disrupted sleep.

A polysomnographer (IM) attached the elec- trodes and transducers prior to the patient's usual "lights out" time and activated the recording device. She then returned early the following morning to remove the electrodes after the usual patient "wake time". There was no trained polysomnographer in attendance for any of the studies and nine out of 42 patients $(21 \%$ of cases) were entirely alone at night. In $\underset{x}{0}$ one study the $\mathrm{Spo}_{2}$ signal was lost, but none of the studies failed.

The polysomnographic recordings were played back through an Oxford Medilog 9200 흠 computer system and displayed on a VDU $\frac{\text { क }}{\vec{D}}$ screen in 30 second epochs for manual scoring $\stackrel{\mathbb{2}}{2}$ of sleep using the standard criteria of Rechtschaffen and Kales. ${ }^{13}$ The respiratory signals $\overrightarrow{0}$ were used to identify apnoeas (absence of airflow for 10 seconds or more) which were then $\vec{\omega}$ classified as either central (absence of re- $\overrightarrow{\vec{x}}$ spiratory motion or effort), obstructive (pres- $x$ ence of respiratory effort), or mixed (central. and obstructive components). Hypopnoeas were defined as a reduction in airflow of $50 \% \vec{\omega}$ or more from baseline, lasting 10 seconds or 을 more.

In addition to the standard polysomno- $\vec{c}$

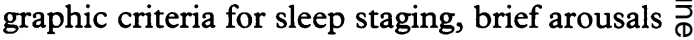
from sleep were scored according to recently $\vec{\theta}$ published criteria. ${ }^{14}$ In general, an arousal requires an abrupt increase in EEG frequency for example, return of alpha rhythm - that lasts for three seconds or more. Such an arousal is often accompanied by other physiological changes such as head movement artefact on $\stackrel{\circ}{D}$ the EEG, EOG, or EMG signals. In this study we also identified sudden runs of $\mathrm{K}$ complexes $\bar{\partial}$ or slow waves that were associated with a sudden increase in the rate or depth of breathing, and/or movement artefacts. These changes were interpreted and scored as arousals although they did not strictly meet the definition of an arousal mentioned above.

\section{OTHER MEASUREMENTS}

Before commencing the sleep study, awake arterial oxygen saturation was recorded (pulse $D$ oximetry). Spirometry was performed including forced and slow vital capacity man- o oeuvres using a calibrated spirometer (Vitalograph, Buckingham, UK). Height was 은 measured with the patient supine, and neck, $\omega$ chest and abdominal circumference recorded with the patient sitting. It was logistically not $\frac{0}{0}$ possible to weigh patients in their homes. Supine blood pressure was recorded. In the evening a battery of neuropsychological tests was administered, the results of which will be reported separately.

\section{DATA ANALYSIS}

The $\chi^{2}$ test was used to examine possible differences in gender ratios between the popu- $\frac{0}{\partial}$ lations included and excluded from the study. The Mann-Whitney test was used to compare respiratory disturbance indices between patients with high and low cervical cord lesions and between those who slept supine and in other postures. The Kruskal-Wallis test was 
Table 1 Clinical, anthropometric and lung function data

\begin{tabular}{lll}
\hline & Mean (SD) & Range \\
\hline Age (years) & $35 \cdot 0(10.5)$ & $19-60$ \\
No. (\%) of patients taking diazepam & $23 \quad(57 \cdot 5 \%)$ & \\
No. (\%) of patients taking baclofen & $30 \quad(75 \%)$ & \\
No. (\%) of patients consuming alcohol & $17 \quad(42 \%)$ & \\
Neck circumference (cm) & $41 \cdot 5(4 \cdot 60)$ & $33-60$ \\
Chest circumference (cm) & $95 \cdot 7(12 \cdot 8)$ & $74-146$ \\
Abdominal circumference (cm) & $93 \cdot 9(20 \cdot 0)$ & $30-160$ \\
FEV 1 (1) & $2 \cdot 53(0 \cdot 77)$ & $1 \cdot 1-4 \cdot 5$ \\
FEV (\% predicted) & $62 \cdot 5(16 \cdot 8)$ & $26-101$ \\
FVC (1) & $2 \cdot 85(0 \cdot 90)$ & $1 \cdot 2-5 \cdot 2$ \\
FVC (\% predicted) & $54 \cdot 3(15 \cdot 7)$ & $21-88$ \\
FEV 1 /FVC (\%) & $89 \cdot 5(8 \cdot 56)$ & $67-100$ \\
Awake Spo $_{2}(\%)$ & $96 \cdot 9(1 \cdot 57)$ & $91-99$ \\
\hline
\end{tabular}

Table 2 Respiratory disturbance index (RDI)

\begin{tabular}{|c|c|c|c|c|}
\hline \multirow[b]{3}{*}{$\mathrm{RDI} \geqslant 5$} & \multicolumn{4}{|c|}{ Percentage of patients ( $95 \%$ confidence intervals) } \\
\hline & \multicolumn{2}{|c|}{ Quadriplegics (current study) } & \multicolumn{2}{|c|}{ Able-bodied population ${ }^{18}$} \\
\hline & $\begin{array}{l}57 \cdot 5 \\
(n=23)\end{array}$ & (46 to 67 ) & 24 & (19 to 28 ) \\
\hline $\mathrm{RDI} \geqslant 10$ & $\begin{array}{l}40 \\
(n=16)\end{array}$ & (32 to 51 ) & 15 & (12 to 19$)$ \\
\hline $\mathrm{RDI} \geqslant 15$ & $\begin{array}{l}27 \cdot 5 \\
(n=11)\end{array}$ & (19 to 33 ) & $9 \cdot 1$ & $(6.4$ to 11$)$ \\
\hline
\end{tabular}

Reference 18 describes 352 men aged 30-60 years randomly selected from a working population.

used to examine the relationship of patients' self reported daytime sleepiness to the frequency of arousals and RDI. The RDI was transformed by $\log 10$ to achieve a normal distribution before using parametric tests of correlation and stepwise multiple linear regression. Tests of correlation were used to examine associations between continuous variables and the dependent variable ( $\log 10$ transformed $R D I)$. Pearson correlation coefficients are reported. Those variables that correlated with RDI were entered into a stepwise multiple linear regression model. A p value of less than 0.05 was considered statistically significant. The standard deviation was used to describe the frequency distribution of a parameter in the entire sample. The standard error was used in comparing means of one group to another.

\section{Results}

PATIENT SELECTION

Ninety one apparently eligible patients were sent a questionnaire and asked to participate in the study. Of these, $65(71 \%)$ replied. Two patients were excluded at this stage because their replies to the questionnaire indicated a significant head injury, or alcohol and drug abuse. Six of the 65 patients indicated they were unwilling to participate in the sleep studies. Eight of the remaining 57 patients were excluded because they were now residing in another state. This left 49 potentially eligible patients who were willing to participate. On close clinical examination seven patients were subsequently excluded because there had been substantial neurological recovery since their injury and they no longer met the inclusion criteria. Therefore, of the initial 91 patients approached, 42 patients $(46 \%)$ were studied. The results of two patients were subsequently eliminated from the analysis because a substantial neurological recovery was confirmed and they were reclassified into the Frankel D category.

To determine whether these 40 patients were representative of the South Australian quadriplegic population we compared the mean age and sex ratios in the 40 patients included in the study (group I) with the other 51 patients (group II) from the original 91 who were either excluded from the study or did not participate for any reason. There were no significant differences in these parameters (mean age 35.0 $(1 \cdot 7)$ years (group I), $31.8(1 \cdot 2)$ years (group II) (NS); sex ratio (M:F) 37:3 (group I), 42:9 (group II) (NS). Unfortunately the information from the national patient registry was not sufficiently complete or up to date to enable us to compare parameters of body mass and medication use in the 40 patients studied with those who did not participate. Responses of the six patients who completed the questionnaire but refused polysomnography did not differ from the questionnaire responses of the participants with respect to the frequency of witnessed apnoeas, choking episodes, or daytime sleepiness.

Clinical, anthropometric, and lung function data of the 40 quadriplegic patients participating in the study are provided in table 1. Predictable reductions in lung function were observed, but mean awake $\mathrm{SpO}_{2}$ was normal. A predictably high percentage of patients took antispasm medications.

\section{SLEEP DISORDERED BREATHING}

Data on sleep disordered breathing are presented in table 2 and compared with recently published data in a normal population. It was found that 11 of 40 patients $(27.5 \%)$ had re-

Table 3 Individual sleep breathing data in 11 patients with $R D I \geqslant 15$

\begin{tabular}{|c|c|c|c|c|c|c|c|c|c|c|c|c|c|}
\hline \multirow{2}{*}{$\begin{array}{l}\text { Patient } \\
\text { No. }\end{array}$} & \multirow[t]{2}{*}{ Sex } & \multirow[t]{2}{*}{ Age } & \multirow{2}{*}{$\begin{array}{l}\text { Neck } \\
\text { circum- } \\
\text { ference }(\mathrm{cm})\end{array}$} & \multirow{2}{*}{$\begin{array}{l}R D I \\
\text { (events/h) }\end{array}$} & \multirow{2}{*}{$\begin{array}{l}\text { Hypopnoea } \\
\text { index } \\
\text { (events/h) }\end{array}$} & \multicolumn{3}{|c|}{ Apnoea index (events/h) } & \multirow{2}{*}{$\begin{array}{l}\text { Awake } \\
\mathrm{SpO}_{2}\end{array}$} & \multicolumn{2}{|c|}{ Minimum $\mathrm{SpO}_{2}$} & \multirow{2}{*}{$\begin{array}{l}\text { Desatur- } \\
\text { ation } \\
\text { index* }(n / h)\end{array}$} & \multirow{2}{*}{$\begin{array}{l}\% \text { of recording } \\
\text { time } \\
\mathrm{SpO}_{2}<90 \%\end{array}$} \\
\hline & & & & & & Central & Obstructive & Mixed & & Non-REM & $R E M$ & & \\
\hline $\begin{array}{r}1 \\
2 \\
3 \\
4 \\
5 \\
6 \\
7 \\
8 \\
9 \\
10 \\
11\end{array}$ & $\begin{array}{l}M \\
M \\
M \\
F \\
M \\
M \\
M \\
M \\
M \\
M \\
M\end{array}$ & $\begin{array}{l}39 \\
32 \\
39 \\
53 \\
41 \\
38 \\
22 \\
60 \\
48 \\
54 \\
40\end{array}$ & $\begin{array}{l}60 \\
48 \\
42 \\
45 \\
48 \\
38 \\
40 \\
42 \\
39 \\
48 \\
42\end{array}$ & $\begin{array}{l}79 \cdot 3 \\
65 \cdot 5 \\
54 \cdot 0 \\
46 \cdot 3 \\
34 \cdot 9 \\
34 \cdot 4 \\
26 \cdot 0 \\
20 \cdot 7 \\
19 \cdot 4 \\
17 \cdot 5 \\
15 \cdot 3\end{array}$ & $\begin{array}{r}0.6 \\
9.7 \\
25.1 \\
3.9 \\
33.0 \\
12.4 \\
4.5 \\
5.1 \\
12.9 \\
7.0 \\
12.3\end{array}$ & $\begin{array}{r}0.0 \\
0.1 \\
4.5 \\
0.0 \\
0.0 \\
0.0 \\
19.9 \\
0.0 \\
0.0 \\
10.5 \\
0.8\end{array}$ & $\begin{array}{r}78.3 \\
55.6 \\
18.4 \\
42.2 \\
1.9 \\
21.6 \\
0.0 \\
15.6 \\
6.5 \\
0.0 \\
2.1\end{array}$ & $\begin{array}{l}0.4 \\
0 \cdot 0 \\
6 \cdot 1 \\
0 \cdot 2 \\
0.0 \\
0 \cdot 3 \\
1 \cdot 6 \\
0.0 \\
0.0 \\
0.0 \\
0.0\end{array}$ & $\begin{array}{l}91 \\
98 \\
96 \\
96 \\
97 \\
98 \\
98 \\
96 \\
98 \\
96 \\
97\end{array}$ & $\begin{array}{l}65 \\
73 \\
80 \\
77 \\
71 \\
79 \\
96 \\
83 \\
85 \\
86 \\
90\end{array}$ & $\begin{array}{l}62 \\
49 \\
71 \\
79 \\
78 \\
80 \\
95 \\
81 \\
81 \\
86 \\
85\end{array}$ & $\begin{array}{r}70 \\
61 \\
36 \\
39 \\
26 \\
13 \\
0 \\
14 \\
5 \\
5 \\
5\end{array}$ & $\begin{array}{r}73 \\
35 \\
11 \\
31 \\
7 \\
8 \\
0 \\
5 \\
1 \\
1 \\
1\end{array}$ \\
\hline $\begin{array}{l}\text { Mean } \\
\text { SD }\end{array}$ & & $\begin{array}{l}42 \cdot 4 \\
10 \cdot 8\end{array}$ & $\begin{array}{r}44 \cdot 7 \\
6 \cdot 2\end{array}$ & $\begin{array}{l}37 \cdot 6 \\
21 \cdot 3\end{array}$ & $\begin{array}{r}11.5 \\
9.7\end{array}$ & $\begin{array}{l}3 \cdot 3 \\
6 \cdot 4\end{array}$ & $\begin{array}{l}22 \cdot 0 \\
26 \cdot 0\end{array}$ & $\begin{array}{l}0.8 \\
1.8\end{array}$ & $\begin{array}{r}96 \cdot 5 \\
2 \cdot 0\end{array}$ & $\begin{array}{r}80.5 \\
8.9\end{array}$ & $\begin{array}{l}77 \cdot 0 \\
12 \cdot 5\end{array}$ & $\begin{array}{l}24.9 \\
23 \cdot 9\end{array}$ & $\begin{array}{l}15 \cdot 7 \\
22 \cdot 5\end{array}$ \\
\hline
\end{tabular}

* Desaturations $\geqslant 4 \%$ from baseline per hour of total time available for sleep. 
Table 4 Mean (SE) sleep architecture in quadriplegic patients compared with normal subjects according to age

\begin{tabular}{|c|c|c|c|c|c|c|c|c|}
\hline & \multicolumn{2}{|l|}{$18-29$} & \multicolumn{2}{|l|}{$30-39$} & \multicolumn{2}{|l|}{$40-49$} & \multicolumn{2}{|l|}{$50-60$} \\
\hline & $\begin{array}{l}\text { Present } \\
\text { study } \\
(n=14)\end{array}$ & $\begin{array}{l}\text { Normal* } \\
\text { subjects } \\
(n=44)\end{array}$ & $\begin{array}{l}\text { Present } \\
\text { study } \\
(n=14)\end{array}$ & $\begin{array}{l}\text { Normal* } \\
\text { subjects } \\
(n=23)\end{array}$ & $\begin{array}{l}\text { Present } \\
\text { study } \\
(n=7)\end{array}$ & $\begin{array}{l}\text { Normal* } \\
\text { subjects } \\
(n=49)\end{array}$ & $\begin{array}{l}\text { Present } \\
\text { study } \\
(n=5)\end{array}$ & $\begin{array}{l}\text { Normal } \\
\text { subjects } \\
(n=41)\end{array}$ \\
\hline \multirow{6}{*}{$\begin{array}{l}\text { Total sleep time (TST), } \min \\
\text { Non-REM sleep (NREM), min } \\
\% \text { of TST } \\
\text { Stage } 1 \\
\% \text { of NREM } \\
\text { Stage } 2 \\
\% \text { of NREM } \\
\text { Stage } 3+4 \\
\% \text { of NREM }\end{array}$} & $385(18 \cdot 8)$ & $347(9 \cdot 4)$ & $393(19 \cdot 7) \dagger$ & $340(14 \cdot 8)$ & $383(23.8) \dagger$ & $329(7 \cdot 8)$ & $403(35.0) \dagger$ & $332(9 \cdot 9)$ \\
\hline & $325(5.4) \ddagger$ & $275(3.8)$ & $340(6.6) \neq$ & $267(5.9)$ & $331(9.4) \ddagger$ & $265(4 \cdot 5)$ & $347(10 \cdot 4) \ddagger$ & $263(4 \cdot 6)$ \\
\hline & $84(1.4) \dagger$ & $79(1 \cdot 1)$ & $87(1 \cdot 7) \dagger$ & $79(1 \cdot 7)$ & $86(2 \cdot 4)$ & $81(1 \cdot 4)$ & $86(2 \cdot 6)$ & $79(1 \cdot 4)$ \\
\hline & $35(6.8) \ddagger$ & $6(0.7)$ & $50(7 \cdot 8) \ddagger$ & $5(0.7)$ & $41(7 \cdot 0) t$ & $8(0.7)$ & $38(7 \cdot 8) \dagger$ & $8(0 \cdot 7)$ \\
\hline & $43(4.9) \ddagger$ & $72(2 \cdot 3)$ & $35(5 \cdot 1) \ddagger$ & $73(3 \cdot 7)$ & $44(5 \cdot 7) \ddagger$ & $79(2 \cdot 7)$ & $43(6.4) \ddagger$ & $81(2.9)$ \\
\hline & $23(5 \cdot 4)$ & $23(1 \cdot 2)$ & $16(2 \cdot 6)$ & $22(2 \cdot 3)$ & $16(2 \cdot 4)$ & $13(1 \cdot 7)$ & $19(3 \cdot 3)$ & $11(1 \cdot 6)$ \\
\hline \multirow{3}{*}{$\begin{array}{l}\text { REM sleep } \\
\text { min } \\
\% \text { of TST }\end{array}$} & & & & & & & & \\
\hline & $60(5 \cdot 4)$ & $72(4 \cdot 4)$ & $53(6 \cdot 6)$ & $73(7 \cdot 5)$ & $53(9 \cdot 4)$ & $64(3 \cdot 9)$ & $57(10 \cdot 4)$ & $69(3.9)$ \\
\hline & $16(1.4) \dagger$ & $21(1 \cdot 3)$ & $13(1 \cdot 7) \dagger$ & $21(2 \cdot 2)$ & $14(2 \cdot 4)$ & $19(1 \cdot 2)$ & $14(2 \cdot 6)$ & $21(1 \cdot 2)$ \\
\hline
\end{tabular}

* Normal subjects (first night sleep laboratory) data derived from reference 16 .

$\dagger \mathrm{p}<0.05 ; \ddagger \mathrm{p}<0.001$ versus normal subjects from the same age group.

spiratory disturbance index (RDI; apnoeas plus hypopnoeas/hour of sleep) of $\geqslant 15$. Among these 11 patients the mean (SD) nadir $\mathrm{Spo}_{2}$ was $76 \cdot 1(12 \cdot 6) \%$ (range $49 \%$ (indicating severe oxygen desaturation) to $95 \%$ (insignificant desaturation)). Relevant sleep and breathing data for these 11 patients are shown in table 3 . Twelve of $40(30 \%)$ had an apnoea index (AI, apnoeas/hour of sleep) of $\geqslant 5$. Of the 12 patients with an $A I \geqslant 5$, nine (75\%) had predominantly obstructive apnoeas - that is, $>80 \%$ of apnoeas were obstructive or mixed. Six of $40(15 \%)$ had an apnoea index of $\geqslant 20 /$ hour, which is a level of breathing disturbance shown in an earlier study to be associated with increased mortality. ${ }^{15}$

Among the 29 patients whose overall sleep RDI was less than 15 there were $16(55 \%)$ who suffered repetitive REM only sleep disordered breathing (REM RDI $\geqslant 15$ ). While the overall sleep RDI in these patients was below the level generally considered to be of clinical concern, some of these patients had moderately severe oxygen desaturation in REM sleep. Mean nadir REM Spo ${ }_{2}$ was $88.6(6 \cdot 4) \%$ (range 80-96\%).

The RDI was correlated with systolic $(r=0 \cdot 36, \mathrm{p}<0.05)$ and diastolic blood pressure $(r=0.32, \mathrm{p}<0.01)$ and neck circumference $(r=0.46, \mathrm{p}<0.005)$. There was no difference in mean rank RDI between patients with high lesions $(C 4-C 5 ; n=16)$ and patients with low lesions (C6-C8; $n=24)$ : mean rank for $R D I$ in patients with high lesions was 24.0 compared with 18.2 in patients with low lesions. Patients who slept supine $(n=25)$ had a higher $R D I$ than those who slept in other postures $(n=15)$ (mean rank RDI supine $=23 \cdot 6$, other postures $=15 \cdot 3, p<0.05)$. RDI did not correlate with measures of lung function. While baclofen and diazepam were administered to a high percentage of the study population $(75 \%$ and $57 \%$, respectively), there was no association between the dose of spasmolytic medication and RDI. All the variables that were found to have a statistically significant association with RDI - that is, blood pressure, neck circumference, and sleep posture - were entered into a multiple stepwise linear regression analysis with $\log 10$ transformed RDI the dependent variable. Only neck circumference and posture were retained by the model as independent predictors of RDI and together they accounted for $33 \%$ of the variance (neck cir- cumference $\mathrm{p}<0.001,21 \%$ of variance; posture $\vec{\omega}$ $\mathrm{p}<0.04,12 \%$ of variance). The regression $\vec{x}$ equation was as follows: $\log 10 \mathrm{RDI}=$ i $0.05 \times$ neck circumference $(\mathrm{cm})+0.38 \times$ \% posture $-1 \cdot 30$, where posture is treated as a $\dot{\sigma}$ dichotomous variable with supine posture $=1 \vec{\omega}$ and other postures $=0$.

Since neck circumference appeared to be associated with sleep disordered breathing in $\subseteq$ our study population we wished to determine $\overparen{D}$ whether neck circumference was greater in our $\vec{\theta}$ population than in a matched non-quadriplegic of population. To do this we compared neck circumference and neck circumference adjusted for height in the 40 quadriplegic patients participating in the study with values obtained in 38 able bodied men (aged between 30 and $50 \stackrel{\square}{\varnothing}$ years), chosen at random among the employees $\overrightarrow{\vec{B}}$ of our institutions. The quadriplegic patients $\frac{0}{3}$ had greater neck circumference $(41.5(0.7) \mathrm{cm})$ than the normal subjects $(38.9(0.4) \mathrm{cm})$ ? $(\mathrm{p}<0.005)$; neck circumference $(\mathrm{cm}) \times 100 /$ height $(\mathrm{cm})$ in quadriplegics was $23.2(0.4)$ 음 compared with $21.7(0.2)$ in normal subjects $\stackrel{x}{x}$ $(p<0.005)$. The mean age was similar for the two groups: quadriplegics $35.0(1 \cdot 7)$ years; normal subjects $36.5(1 \cdot 2)$ years (NS).

SLEEP COMPLAINTS AND SLEEP ARCHITECTURE

Six patients (15\%) "often" complained of ex- $\sigma$ cessive daytime sleepiness, $13(32 \cdot 5 \%)$ "some- N times", five $(12.5 \%)$ "rarely", and 16 patients $(40 \%)$ "never" complained of daytime sleepiness. The degree of self reported daytime sleep-o iness was directly related to the frequency of $\frac{\mathscr{D}}{\mathscr{D}}$ sleep arousals of all types $(p=0.02)$ but not $\stackrel{\mathcal{P}}{+}$ with respiratory arousals alone - that is, $\frac{0}{0}$ arousals following apnoeas or hypopnoeas. $\frac{\vec{d}}{\vec{D}}$ Sleep architecture for various age categories is $\frac{\rho}{\Phi}$ shown in table 4 and compared with normative $\stackrel{\square}{\Omega}$ data from the literature. ${ }^{16}$ There was evidence? of considerable sleep disturbance in the quadri- 8 plegic population studied with a consistent in-을 crease in the percentage of stage 1 and $a \frac{\overline{0}}{0}$ corresponding decrease in the percentages of stage 2 and REM sleep across all age groups compared with a control population. REM sleep appeared to be reduced both in minutes and as a percentage of total sleep time. Total sleep time was increased compared with previously published normal values. ${ }^{16}$ 


\section{Discussion}

The main findings of this study were that 25$30 \%$ of stable quadriplegic patients had significant sleep disordered breathing and that the main abnormality of breathing was obstructive sleep apnoea rather than central apnoea or hypoventilation. The findings were particularly striking given the young age of the patients. In none of the affected patients had sleep apnoea been previously diagnosed. We think it is unlikely that selection bias could explain the high prevalence of sleep disordered breathing in our study. Firstly, the age and sex distribution of the 40 patients studied was not different from that among the patients who were potentially eligible but were not studied. Therefore, the patients studied could not have had a higher prevalence of sleep disordered breathing because of older age or because of a greater preponderance of males. Secondly, there is no reason to believe that the patients excluded on the basis of domicile - that is, residing in another state - would have a higher or lower prevalence of sleep breathing problems. Thirdly, there was no difference in symptoms of sleep disordered breathing (snoring, choking episodes, daytime sleepiness) in the six patients who responded to the questionnaire but declined polysomnography, and the 40 who were studied. However, we have no information on body mass or sleep symptoms in 26 patients originally approached, and it is impossible therefore to totally exclude some selection bias. We believe the study population was representative of all quadriplegic patients in our state and is similar to quadriplegic patients in other centres with respect to sex distribution and age. ${ }^{17}$ The home polysomnography is unlikely in our opinion to have led to an overestimation of sleep disordered breathing or sleep disturbance. The quality of the recordings was excellent, attributable in part perhaps to the relatively fixed sleeping position of our subjects, and it is likely that polysomnographic recordings conducted in a familiar setting would, if anything, lead to fewer sleep disturbances than in a laboratory.

The observed prevalence of sleep disordered breathing appears to be much higher than expected from previously published sleep study data in normal subjects (see table 1). A recent polysomnographic study of a randomly chosen sample of over 600 working men and women (30-60 years of age) showed the prevalence of sleep disordered breathing (defined as $\mathrm{RDI} \geqslant 15$ ) to be $9 \cdot 1 \%$ for men and $4 \%$ for women. ${ }^{18}$ This compares with a prevalence $(R D I \geqslant 15)$ of $27.5 \%$ in the present study population. While there was an expected marked sex bias towards males in the quadriplegics studied, and snoring and obstructive apnoea is more common in men, previous data on sex differences obtained in a healthy population indicate that this would not be sufficient to explain the findings. ${ }^{18}$

POSSIBLE CAUSES OF SLEEP DISORDERED BREATHING

We had anticipated that the major sleep breathing abnormalities in quadriplegia would be central apnoea and prolonged sleep hypoventilation due to sleep-induced failure of already weakened inspiratory muscles. The finding of predominantly obstructive apnoeas was unexpected, although a recent study in an older spinal injury population raised this possibility. ${ }^{11}$ The spinal cord injury itself would not have directly affected the motor innervation of dilator muscles of the upper airway such as the genioglossus and geniohyoid. One possible explanation is that the medication taken to control spasticity may have led to increased upper airway hypotonia in sleep and thereby more obstructive breathing events. Baclofen was administered to $75 \%$ of the study population. This is a GABA agonist that has been shown experimentally to decrease ventilation and ventilatory responsiveness to hypercapnia and hypoxia. ${ }^{19}$ However, we recently conducted a placebo controlled trial ${ }^{20}$ of the effects of a single nocturnal $25 \mathrm{mg}$ dose of baclofen on sleep disordered breathing in a group of patients with a history of persistent snoring and found only a very small decrease of baseline $\mathrm{SpO}_{2}$ and no increase in disordered breathing events. Based on these findings we think it unlikely that nocturnal administration of baclofen alone would explain the high frequency of obstructive breathing events in our quadriplegic population. Furthermore, in the present study baclofen dose did not correlate with RDI. Another central nervous system depressant, diazepam, was taken by $57 \%$ of our study population. Benzodiazepines have been shown to increase sleep disordered breathing. ${ }^{2-4}$ The mean dose of diazepam administered at night in our study $(8.2 \mathrm{mg})$ may have been sufficient to induce some sleep disordered breathing. ${ }^{21}$ However, like baclofen, there was no correlation between nocturnal diazepam dose and RDI. Another possible explanation for the high prevalence of disordered breathing is the sleep posture of quadriplegic patients; $63 \%$ of the study population spent the entire study night supine, a sleeping position known to be associated with increased upper airways obstruction.

It was found that the frequency of disordered breathing events in sleep correlated with neck circumference, an observation that fits with earlier findings in non-quadriplegic populations. ${ }^{22-24}$ The possibility arises from these data that the high prevalence of sleep disordered breathing in our population may have been due to increased neck circumference which in turn may have been related to increased body mass. Indeed, we found that mean neck circumference in our study population was greater than that in a matched, able-bodied healthy population. There are other potential explanations for an increase in neck circumference in quadriplegic patients apart from a generalised increase in body mass - for example, neck muscle hypertrophy, redistribution of body fat. However, we think these explanations less likely since in a preliminary analysis of our results we found that abdominal, chest, and neck circumferences were significantly correlated with one another and each was correlated with the frequency of sleep dis- 
ordered breathing events. We chose to report data for neck circumference and not abdominal and chest circumferences since this measurement correlated best with RDI. Also, it has been shown in earlier studies ${ }^{22-24}$ to be related to body mass and to be predictive of sleep disordered breathing. While we did not have a direct measurement of body mass in our study, we consider that these data strongly suggest that obesity and neck size are important contributory factors to sleep apnoea in patients with quadriplegia.

The multiple stepwise linear regression model showed neck size and posture to be the only independent predictors of sleep disordered breathing. Neck circumference was the major determinant of sleep disordered breathing with sleep posture apparently having a lesser effect.

\section{CLINICAL IMPLICATIONS OF THE PRESENT} FINDINGS

It has been shown in previous studies that sleep apnoea is associated with increased daytime sleepiness, ${ }^{25}$ cognitive impairment, ${ }^{26}$ and increased cardiovascular morbidity and mortality. ${ }^{152728}$ A significant proportion (45\%) of our study population complained of daytime sleepiness. Daytime sleepiness appeared to be related to the presence of fragmented sleep although it seems from our data that the sleep fragmentation was not explained entirely by apnoea or hypopnoea associated arousals. Further investigation is required to determine if there are other causes of sleep arousals and sleep disturbances in this population such as upper airways resistance syndrome. ${ }^{29}$ Age adjusted sleep architecture appeared to be abnormal in the study population as a whole with increased percentages of stage 1 non-REM (light sleep), decreased stage 2 non-REM, and decreased REM sleep (table 4). Daytime sleepiness is likely to have special significance in this population since it impacts most on sedentary activities such as reading and television viewing which may assume greater importance in quadriplegic than in non-quadriplegic populations.

Recent studies have indicated that untreated obstructive sleep apnoea is associated with increased cardiovascular mortality. ${ }^{152728}$ In one study patients with an apnoea index of $>20$ / hour had a cumulative mortality of approximately $20 \%$ at five years. ${ }^{15}$ The cause of death in patients with sleep apnoea appears to be due mainly to sudden cardiovascular events such as stroke and myocardial infarction. ${ }^{28}$ In the present study six patients $(15 \%)$ were found to have an apnoea index of $>20 /$ hour of sleep, placing them potentially in a high risk category. Whether quadriplegic patients are more or less vulnerable to the cardiovascular complications of sleep apnoea is not known. There have been a number of studies showing an association between snoring/sleep apnoea and systemic hypertension, ${ }^{30-32}$ although there is controversy as to whether sleep disordered breathing is a truly independent risk factor and whether the increased prevalence of hypertension in patients with sleep apnoea might not instead be explained by obesity. ${ }^{23}$ In the present study sys- tolic and diastolic blood pressures correlated with the frequency of disordered breathing events during sleep. There was no association found between blood pressure and an index of body mass (neck circumference). Only two (5\%) of the patients could be considered to be hypertensive by conventional criteria (diastolic pressure $>95 \mathrm{~mm} \mathrm{Hg}$ ). The disruption of $\stackrel{\nexists}{\times}$ normal sympathetic reflex innervation could $\Rightarrow$ conceivably provide some protection in quad- $\frac{9}{9}$ riplegic patients with sleep apnoea against sudden arrhythmias and the development of hypertension.

Treatment options in able-bodied patients $\stackrel{\nabla}{\triangle}$ with obstructive sleep apnoea include weight के reduction, removal or reduction of sedating $\overrightarrow{0}$ substances, surgical correction of specific abnormalities of the upper airway, and, in mod- $\vec{\omega}$ erate to severe cases, nasal continuous positive airway pressure (CPAP) at night. ${ }^{33}$ Because of $\times$ the statistical association between neck circumference and supine sleep posture with RDI $\sigma$ observed in the present study, some quad- $\vec{\omega}$ riplegic patients may respond to weight re- 을 duction or changing sleep position. Minimising the use of sedating antispasm medications is logical although we have no evidence from this $\underset{\phi}{\Phi}$ study (see above) that these medications were $\vec{\bullet}$ responsible for sleep disordered breathing in of our population. Specific upper airways anatomical abnormalities have not been detected in any of our patients. The use of nasal CPAP should be recommended to the more severely affected patients and may require special care and closer follow up, particularly in those patients who are unattended at night.

In conclusion, we have shown in a representative sample population of quadriplegic patients a prevalence of potentially serious sleep disordered breathing which is more than twice that previously reported in an able-bodied $\underset{x}{x}$ population of similar age and sex distribution. Sleep disordered breathing in quadriplegics appears to be mainly obstructive in type and $\delta$ to be strongly associated with increased neck circumference, as it is in able-bodied patients, 을 and to be more significant in those patients $D$ who sleep supine. It is associated with higher systolic and diastolic blood pressure. Quadri- No plegic patients appear to have disrupted sleep patterns and complain frequently of excessive $N$ daytime sleepiness which may, at least in part, $\omega$ be the result of sleep apnoeas and hypopnoeas. Further investigation is required to evaluate the full clinical significance of sleep disordered $\cong$ breathing in quadriplegic patients, its causes and treatment.

We wish to acknowledge the Julia Farr Centre Research Foundation Inc and the Royal Adelaide Hospital Special Purposes Fund for their financial support, FSE for providing the portable monitoring and analysis systems (Oxford Medilog 9200); the (1) patients, Quadcare, for pro-

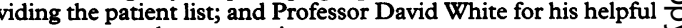
comments on the manuscript.

1 Olson LG, Hensley MJ, Sullivan CE, Saunders NA. Sleep, breathing and lung disease. In: Saunders NA, Sullivan $\mathrm{CE}$, eds. Sleep and breathing. Lung biology in health and disease. Vol 21. New York: Marcel Dekker, 1984:517-58.

2 Guilleminault C, Cummiskey J, Silvestri R. Benzodiazepines and respiration during sleep. In: Usdin E, Skolnick P, Tallmen JF, et al, eds. Pharmacology of benzodiazepines. London: Macmillan, 1978:229-36.

3 Mendelson WB, Garnett D, Gillin JC. Flurazepam induced 
sleep apnea syndrome in a patient with insomnia and mild sleep-related respiratory changes. 7 Nerv Ment Dis 1981 ; 169:261-4.

4 Dolly FR, Block AJ. Effect of flurazepam on sleep-disordered breathing and nocturnal oxygen desaturation in asymptobreathing and nocturnal oxygen desaturation

5 Schmid K, Bohmer G, Gebauer K. GABA ${ }_{B}$ receptor mediated effects on central respiratory system and their antagonism by phaclofen. Neurosci Lett 1989;99:305-10.

6 Kelling JS, MiMarco AF, Gottfried SB, Altose MD. Respiratory responses to ventilatory loading following low cervical spinal cord injury. $₹$ Appl Physiol 1985;59:1752-6.

7 Flavell H, Marshall R, Thornton AT, Clements PL, Antic $\mathrm{R}$, McEvoy RD. Hypoxia episodes during sleep in high tetraplegia. Arch Phys Med Rehab 1992;73:623-7.

8 Cahan C, Gothe B, Decker MJ, Arnold JL, Strohl KP. Arterial oxygen saturation over time and sleep studies in quadriplegic patients. Paraplegia 1993;31:172-9.

9 Braun SR, Giovannoni BA, Levin AB, Harvey RF. Oxygen saturation during sleep in patients with spinal cord injury. Am $\mathcal{F}$ Phys Med 1982;61:302-95.

10 Bonekat HW, Andersen G, Squires J. Obstructive disordered breathing during sleep in patients with spinal cord injury. Paraplegia 1990;28:392-8.

11 Short DJ, Stradling JR, Williams SJ. Prevalence of sleep apnoea in patients over 40 years of age with spinal cord lesions. 7 Neurol Neurosurg Psychiatry 1992;55:1032-6.

12 Hoelscher TJ, McCall WV, Powell J, Marsh GR, Erwin $\mathrm{CW}$. Two methods of scoring sleep with the Oxford Medilog 9000: comparison to conventional paper scoring. Sleep 1989;12:133-9.

13 Rechtschaffen A, Kales A. A manual of standardised terminology, techniques and scoring system for sleep stages of human subjects. Los Angeles: Brain Information Service/ Brain Research Institute, UCLA, 1968.

14 Atlas Task Force of the American Sleep Disorders Association. EEG arousals: scoring rules and examples. Sleep 1992;15:174-84.

15 He J, Kryger MH, Zorick FJ, Conway W, Roth T. Mortality and apnea index in obstructive sleep apnea. Chest 1988; 94:9-14.

16 Hirshkowitz M, Moore CA, Hamilton CR, Rando KC, Karacan I. Polysomnography of adults and elderly: sleep architecture, respiration, and leg movement. $\mathcal{F}$ Clin Neurophysiol 1992;9:56-62.

17 Walsh JE, Actuarial research into physical disablement. Vol 2. New South Wales, Australia: Hunters Hill, 1988.

18 Young T, Palta M, Dempsey J, Skatrud J, Weber S, Badr $S$. The occurrence of sleep disordered breathing among middle-aged adults. N Engl f Med 1993;328:1230-5.
19 Yamada KA, Hamosh P, Gillis RA. Respiratory depression produced by activation of GABA receptors in hind brain of cat. F Appl Physiol 1981;5:1278-86.

20 Finnimore AJ, Roebuck M, Sajkov D, McEvoy RD. The effects of the GABA agonist baclofen on sleep and breathing. Eur Respir $\mathcal{F} 1995$ (in press).

21 Leiter JC, Knuth SL, Krol LC, et al. The effect of diazepam on genioglossal muscle activity in normal human subjects. Am Rev Respir Dis 1985;132:216-9.

22 Smith PL, Gold AR, Meyers DA, Haponik EF, Bleecke ER. Weight loss in mildly to moderately obese patients with obstructive sleep apnea. Ann Intern Med 1985;103: 850-5.

23 Davies RJ, Ali NJ, Stradling JR. Neck circumference and other features in the diagnosis of the obstructive sleep apnoea syndrome. Thorax 1992;47:101-5.

24 Davies RJO, Stradling JR. The relationship between neck circumference, radiographic pharyngeal anatomy, and the obstructive sleep apnoea syndrome. Eur Respir $\mathcal{F} 1990 ; 3$ 509-14.

25 Lavie P. Incidence of sleep apnea in a presumably healthy working population: a significant relationship with $\mathrm{ex}-$ cessive daytime sleepiness. Sleep 1983;6:312-8.

26 Guilleminault $\mathrm{C}$. Clinical features and evaluation of obstructive sleep apnea. In: Kryger $\mathrm{MH}$, Roth T, Dement WC, eds. Principles and practice of sleep medicine. Philadelphia: WB Saunders, 1989:552-8.

27 Hung J, Whitford EG, Parsons RW, Hillman DR. Association of sleep apnoea with myocardial infarction in men. Lancet 1990;336:261-4.

28 Partinen M, Guilleminault C. Daytime sleepiness and vascular morbidity at seven-year-follow-up in obstructive sleep apnea patients. Chest 1990;97:27-32.

29 Guilleminault C. Stoohs R, Clerk A, Simmons J, La banowski $M$. From obstructive sleep apnea syndrome to upper airway resistance syndrome: consistency of daytime sleepiness. Sleep 1992;15(Suppl 6):S13-6.

30 Levinson PD, Millman RP. Causes and consequences of blood pressure alterations in obstructive sleep apnea. Arch Intern Med 1991:151:445-62.

31 Millman RP, Redline S, Carlisle CC, Assaf AR, Levinson PD. Daytime hypertension in obstructive sleep apnea prevalence and contributing risk factors. Chest 1991;99: $861-6$.

32 Hoffstein V, Chan CK, Slutsky AS. Sleep apnea and systemic hypertension: a casual association review. Am f Med 1991; 91:190-6.

33 Sullivan CE, Issa FG, Berthon-Jones M, Eves L. Reversa of obstructive sleep apnea by continuous positive airway pressure applied through the nares. Lancet 1981;i:862-5. 